\title{
Desafios no ensino da íngua portuguesa em contextos multilíngues: a educação nos PALOP
}

\author{
Viviane Lourenço TEIXEIRA 『 \\ Universidade Federal Fluminense (UFF)
}

\section{RESUMO}

Esta resenha destaca pontos relevantes que foram abordados pelos professores que compuseram a mesa redonda, que está inserida nos estudos de sociolinguística. O contexto multilíngue de ensino de língua portuguesa nos Países Africanos de Língua Oficial Portuguesa (PALOP) foi tema central com destaque para Guiné-Bissau, Angola e Cabo Verde. Os conferencistas apresentaram um quadro de como o ensino de língua portuguesa nesses países ainda carece de debates que evidenciem a complexidade linguística por qual passam os estudantes, que nos sistemas educacionais se deparam com a língua portuguesa, seja ela como língua materna ou L2. Como bem afirma o professor e moderador dessa mesa, Alexandre António

EDITADO POR Timbane, é preciso ter um espaço de debate para o compartilhamento de soluções que busquem o melhoramento na qualidade da educação do ensino da língua portuguesa em contextos multilíngues.

\section{RESUMEN}

Esa revisión destaca los puntos relevantes que fueron abordados por los profesores que formaron la mesa redonda, que se inserta en los estudios de sociolingüística. El contexto multilingüe de la enseñanza de la lengua portuguesa en los Países Africanos de Lengua Portuguesa (PALOP) fue un tema central con énfasis en Guinea-Bissau, Angola y Cabo Verde. Los oradores presentaron una imagen de cómo la enseñanza del portugués en estos países aún carece de debates que resalten la complejidad lingüística que experimentan los estudiantes, quienes en los sistemas educativos enfrentan el idioma portugués, sea como lengua materna o L2. Como afirma 


\section{REVISTA DA ABRALIN}

acertadamente el profesor y moderador de esta mesa, Profesor Alexandre António Timbane, debe haber un espacio de debate para compartir soluciones que busquen mejorar la calidad de la educación en la enseñanza de la lengua portuguesa en contextos multilingües.

\section{PALAVRAS-CHAVE}

Ensino. Multilinguismo. Língua portuguesa.

\section{PALABRAS CLAVE}

Enseñanza. Multilingüismo. Lengua portuguesa.

No dia 28 de julho de 2020, os professores Nélia Maria Pedro Alexandre, Eduardo David Ndombele e Amália Maria Vera-Cruz de Melo Lopes apresentaram debates sobre situações de ensino de língua portuguesa em contextos multilíngues nos Países Africanos de Língua Oficial Portuguesa (PALOP). Na mesa redonda on-line, no site da Associação Brasileira de Linguística (Abralin,), intitulada A educação nos PALOP: Avanços e Caminhos para o ensino da língua portuguesa em contextos multilingues, os professores conferencistas trataram da relevância das situações de multilinguismo dentro das escolas que integram os PALOP e dos desafios no ensino de português.

A primeira apresentação da mesa foi da professora Nélia Maria Pedro Alexandre, professora da Faculdade de Letras da Universidade de Lisboa. Ela trouxe enquadramento histórico e sociolinguístico de Guiné-Bissau. Em sua exposição apresentou dados sobre a língua oficial, língua nacional e línguas autóctones. Um fator em sua contextualização histórica é a Conferência de Berlim e a ocupação da costa da Guiné-Bissau e das Ilhas de Cabo Verde, fato este que resultou na formação do crioulo de base lexical portuguesa. Visto que o português foi implementado para uma minoria (especialmente nas grandes cidades) nessa região e era preciso uma língua de comunicação entre nativos e colonizadores. A criação de novas línguas a partir da mistura de duas ou mais que entram em contato é parte de uma das categorias de contato linguísticos que envolvem, além da criação de pidgins e crioulos, a manutenção da língua e a language shift (WINFORD, 2003).

A professora Nélia ressaltou as medidas repressivas de linguísticas e as estratégias educativas "fortes" que "tem como objetivo difundir o patrimônio histórico e cultural português" ${ }^{\text {, durante o }}$ Estado Novo; a fundação em 1956 do PAIGC, por Amílcar Cabral (apontado pela professora Nélia como aquele que desde sempre se preocupa profundamente com a questão educacional do país); e a criação de escola-piloto.

No pós-independência ela nos forneceu dados que comprovam que Portugal não se preocupou em fazer investimentos educacionais, o que deixou a sociedade guineense, assim como as outras 


\section{REVISTA DA ABRALIN}

colônias africanas, com resultados ruins no que diz respeito à educação. Destacou também o estudo do crioulo como língua de ensino, instrução (utilizada por professores) e como língua veicular.

Nélia sustentou que os pais guineenses não valorizaram a escola, como uma resistência natural a esse espaço. Ela apontou que há 3 tipos de resistência: completa, parcial e seletiva. Com dados de 2013 mostrou a falta de uma mudança educacional no país, a manutenção da evasão escolar, o baixo nível de pessoas alfabetizadas e o pouco investimento público.

Com a pergunta "Português da Guiné-Bissau?" retornou ao questionamento feito em sua abordagem que apontou o português como sendo a língua falada por uma minoria com diferentes graus de proficiências. Nélia Maria afirmou que o contato linguístico - segundo Thomason (2001) o contato linguístico pode ser definido quando dois ou mais grupos, com suas respectivas línguas, entram em contato e interagem entre si em um mesmo ambiente - entre o português e o crioulo, gera entre outras coisas empréstimos linguísticos que em sua apresentação são listados.

Nélia trouxe à luz uma perspectiva comparada desses produtos do contato em um cenário multilíngue repleto de falantes plurilíngues. Destacou os impactos desses produtos no ensino, no qual a língua portuguesa, ensinada como língua materna, acaba afetando negativamente a população. E fez um alerta que disse que não valorizar o "repertório linguístico dos alunos é desvalorizar as línguas que eles falam". Como um possível caminho a ser seguido ela afirmou que é preciso investimento na formação dos docentes de forma contínua.

A segunda apresentação foi do professor Eduardo David Ndombele, professor auxiliar do Instituto Superior de Ciências de Educação do Uíge (Angola). Ele chamou a atenção para a problemática do ensino de língua portuguesa em contexto multilíngue. Tendo como cenário Angola e o multilinguismo no processo escolar que tem a língua portuguesa como L2, ressaltou que no período em que Angola fazia parte do domínio de Portugal e mesmo depois de sua independência, o sistema educacional era organizado em português o que marginalizava as línguas faladas pela população angolana.

O pesquisador nos informou que o papel da língua portuguesa é plurifuncional de usos em variados domínios e, como língua oficial e também a utilizada no processo de ensino ${ }^{2}$, é responsável pela comunicação entre grupos etnolinguísticos. Apresentou dados que demostraram que Portugal obrigava o uso e o ensino da língua portuguesa em Angola, à época da colonização. Sabe-se que o país lusitano desde seu projeto de expansão marítima objetivava não só dominar os mares e as rotas comerciais, mas também aumentar seu poderio linguístico. Segundo Faraco (2019, p.95), "a partir de meados do século XV, a língua portuguesa na esteira da expansão marítima de Portugal, sai de suas fronteiras europeias e se torna uma língua internacional [...]".

Dentre seus apontamentos, sublinhou que no pós-independência não só Angola, mas também os países que compõe os PALOP, não tiveram como escolher sua língua de escolarização ${ }^{3}$. Reforça

2 O professor afirma que há um respaldo na Lei Constitucional de Angola.

3 Surge na exposição do pesquisador o termo "política exoglótica". Segundo o professor Eduardo consiste na escolha apenas da língua do colonizador como aquela que seria oficial. 


\section{REVISTA DA ABRALIN}

ainda que atualmente o português como única língua oficial é o que "liga os angolanos", visto que não há comunicação efetiva em outras línguas.

Finda sua exposição abordando questões sobre a realidade dos alunos que não têm o português como língua materna e as consequências que eles sofrem. Falta de compreensão, integração linguística, incompreensão mútua entre professor-aluno e interferências, são listadas por ele. Soluções como a cooficialização e o bilinguismo no contexto escolar são apontados como possíveis elucidações para essa problemática. Termina afirmado que o insucesso escolar em Angola, relaciona-se em grande parte com o problema da língua.

Por último e não menos importante, tem-se a exposição da professora Amália Maria Vera-Cruz de Melo Lopes, professora da Universidade de Cabo Verde. A pesquisadora discorreu sobre a desconsideração do sistema de ensino do ponto de visto linguístico em Cabo Verde. Em contrapartida ao que foi falado pelo professor Eduardo, no que tange à situação linguística em Angola, a professora Amália informou que em Cabo Verde a língua portuguesa não se faz necessária para a compreensão entre os falantes, pois há uma língua cabo-verdiana em crioulo ${ }^{4}$ de base lexical portuguesa como língua veicular. Ressalta, porém, que esta não possui escrita sistemática e que é o português a língua oficial e de fator identitário para muitos cabo-verdianos.

A conferencista assegurou que há uma expansão da língua cabo-verdiana nos contextos formais e uma expansão da língua portuguesa em contextos informais. Segundo ela, há uma expectativa no que diz respeito ao domínio da língua portuguesa em um nível elevado de proficiência, mesmo que a situação se apresente de modo deficiente, visto que não há bons resultados no ensino de português.

Contradições sobre essas práticas nos é apresentada, dentre elas destaca-se: o questionamento do ensino da língua portuguesa e o não investimento nos sistemas de ensino. A professora chama a atenção para as práticas em sala de aula, pois é preciso ter uma coerência entre o que os programas orientam e o que de fato é feito.

Apontou alterações que estão sendo feitas no sistema de ensino, sem uma devida justificação que as fundamente, o que gera, de acordo com ela, incoerências e rupturas. Salientou como ponto importante determinadas práxis educativas, produções que envolvem a oralidade e a escrita e seus conteúdos, que somados contribuiriam para um melhor desenvolvimento do ensino.

Para Amália, a falta de definição nos níveis de proficiência nos ciclos de ensino configura-se como um problema. Ao abordar as capacidades de uso de uma língua e sua compreensão, a professora dialogou com a definição de indivíduo bilíngue que para Li Wei (2000) é aquele ser que possui duas ou mais línguas, levando-se em conta aqueles com seus diferentes graus de capacidades - proficiências.

Levantando a questão sobre a desconsideração da língua materna, afirmou que o ponto decisivo é ensinar o português como língua materna. Por ser a única língua de escolarização, de acordo com a professora, causa uma discrepância com a situação linguística que em seu ponto de vista permanece não proporcional no sistema de ensino cabo-verdiano. A fato da imposição desse ensino,

4 De acordo com a Amália Maria essa língua se apresenta em contextos informais e formais, é utilizada de forma "espontânea" pelos jovens. Contudo, não é reconhecida como língua oficial e consequentemente não é ensinada. 


\section{REVISTA DA ABRALIN}

somado a outros aspectos, gera entre outras coisas listadas por Amália, situações negativas, vergonha e uma "violência simbólica".

Expõe contradições do sistema educacional de Cabo Verde e apresenta problemas, que são somados àqueles já apresentados. Reforça novamente que os avanços não ocorrem efetivamente por falta de apoio institucional e que os professores e sua formação pedagógica são peças fundamentais nesse processo de ensino.

Em síntese, podemos afirmar que a mesa reitera a importância de pesquisas cujo escopo seja o ensino de língua portuguesa nos espaços escolares dos PALOP. O anseio por perspectivas para as diversas situações apresentadas envolve aspectos sociolinguísticos, a fim de trazer não só benefícios, mas também soluções para que o ensino nesses espaços esteja livre de preconceitos.

\section{REFERÊNCIAS}

A educação nos PALOP: avanços e caminhos para o ensino da língua portuguesa em contextos multilíngues. Conferência apresentada por Nélia Maria Pedro Alexandre, Eduardo David Ndombele, Amália Maria Vera-Cruz de Melo Lopes. [s.l., s.n], 2020. 1 vídeo (2h 35min 01s). Publicado pelo canal da Associação Brasileira de Linguística. Disponível em: https://www.youtube.com/watch?v=STITioEnIu0. Acesso em: 28 jul 2020.

FARACO, Carlos Alberto. História do português. São Paulo: Parábola, 2019.

THOMASON, Sarah G. Language contact: an introduction. Edinburgh: Edinburgh University Press, 2001. pp. 1-14.

WEI, Li. Dimensions of Bilingualism. In: Li Wei (Ed.), The Bilingualism Reader, 2000, p. 2-21.

WINFORD, Donald. An introduction to contact linguistics. Oxford: Blackwell, 2003. 